\title{
Os Mitos dos Cientistas e suas Controvérsias
}

The myths of the scientists and their controversies

\author{
Rodrigo Moura \\ (rodrigobarba@zipmail.com.br) \\ João Batista Garcia Canalle \\ (canalle@uerj.br) \\ Instituto de Física, UERJ
}

Recebido em 25/04/2000. Manuscrito revisado em 21/02/2001. Aceito em 29/05/2001

\begin{abstract}
Este artigo discute os mitos que cercam alguns dos maiores cientistas que já existiram e as controvérsias sobre os mesmos. Muitas vezes esses mitos constam em livros didáticos e de divulgação científica de forma inquestionável; são relatados da forma mais fantástica possível, com o louvável intuito de provocar interesse pela ciência, mas que terminam por mostrá-la inacessível às pessoas comuns, pois quase sempre as descobertas científicas por eles relatadas derivam de genialidades. Quando o caso não é esse, tais textos provocam uma desvalorização do trabalho científico, pois mostram as grandes descobertas como resultado do acaso. Para ilustrar certas controvérsias sobre determinados mitos foram escolhidos alguns dos mais célebres personagens da Ciência: Arquimedes, Galileu, Newton, Edison e Einstein. O artigo visa mostrar ao leitor que por trás de um mito geralmente há inúmeras controvérsias sobre as quais se debruçam os pesquisadores em história das ciências, o que geralmente não é divulgado.
\end{abstract}

This article intends to discuss the myths that surround some of the greatest scientists that already existed, and the controversy of the same ones. A lot of times, those myths appear in didact and in scientific popularization books in a incontestable way. They are frequently told in the possible most fantastic way, with the praiseworthy intent of provoking interest in the science, but that end up showing it is inaccessible to the common people since most of the times the scientific discovery reported by them are put as a result of geniality. Otherwise, when this is not the case they devaluate it, showing the great discoveries as a result of the fortuity. To illustrate certain controversies on certain myths we chose some of the most celebrated characters of the science: Archimedes, Galileu, Newton, Edison and Einstein. The article has the purpose to show to the reader that there are countless controversies behind a myth, which discussion among researchers in history of the sciences generally is not disclosed.

\section{Introdução}

A história da ciência está repleta de maravilhosos apólogos ${ }^{1}$. Tais apólogos, quando devidamente relatados, constituem o melhor modo de divulgar a ciência de uma forma interessante e divertida. Várias pessoas conhecem as histórias que cercam os mais célebres cientistas de todos os tempos e perguntam-se o quão de verdade há nelas. Eis algumas, como exemplo: Arquimedes [287 - 212 a. C.] encontrou, enquanto tomava banho, o meio de determinar o peso específico dos corpos e consagrou tal descoberta com o seu famoso "Heureca!"; Benjamin Franklin [1706 - 1790] descobriu que o relâmpago é uma forma de eletricidade ao empinar uma pipa numa tempestade; James Watt [1736 - 1819] percebeu a potência do vapor olhando, quando ainda era menino, a tampa desenfreada da panela, na cozinha de sua tia; Galileu [1564 - 1642] descobriu a lei do isocronismo das oscilações pendulares ao observar o balanço de um lustre na catedral de Pisa; Isaac Newton [1643 - 1727] teria descoberto a lei da gravitação universal quando uma maçã caiu-lhe na cabeça; Alexander Fleming [1881 - 1955] descobriu acidentalmente em 1928 o primeiro grande antibiótico moderno, a penicilina; Einstein era péssimo aluno em Matemática quando criança, e assim por diante. Inúmeros outros mitos poderiam ser citados, mas para não tornar este artigo demasiado longo, serão relatados aqui apenas alguns

\footnotetext{
${ }^{1}$ Apólogo: Historieta mais ou menos longa, que ilustra uma lição de sabedoria e cuja moralidade é expressa como conclusão (fábula)
} 
que portam histórias tidas como verdadeiras mas que, na verdade, ou foram deturpadas ou são pura fantasia, ou ainda, sobre as quais não há um parecer definitivo mesmo entre os historiadores da ciência.

\section{Arquimedes, o sábio de Sira- cusa}

Sem dúvida, Arquimedes foi o mais genial matemático da Antigüidade e o primeiro dos verdadeiros físicos. Filho do astrônomo Fídias, demonstrou desde cedo como virtudes a inteligência e a curiosidade. Seu pai era amigo íntimo do rei Hierão e, dessa forma, Arquimedes recebeu oportunidades de desenvolver em terras distantes suas habilidades.

Ainda menino, viajou ao Egito como discípulo do matemático e astrônomo Conão. Na terra dos faraós, Arquimedes dedicou-se a medir as pirâmides e a tentar desvendar o mistério sobre o processo de construção dos antigos monumentos. Tempos depois, continuou seus estudos em Alexandria, a cidade fundada por Alexandre, O Grande [356 a.C. - 323 a.C.], um dos centros de difusão cultural do mundo antigo.

Ao retornar a Siracusa, foi recebido como um sábio e tratou de manter a boa reputação. Sua obra científica tornou-se considerável: inventou o cálculo de pi pelo método dos perímetros e dos isoperímetros (aumentando-se o número de lados dos polígonos, estes tendem a tornar-se cada vez mais próximos do círculo, em forma e área, até confundirem-se, praticamente) e estudou os sólidos gerados pela rotação das cônicas em torno de seus eixos; são atribuídas a ele as invenções da alavanca ("Dêem-me um ponto de apoio e erguerei o mundo", teria dito), da roda dentada, da roldana móvel e da rosca ${ }^{2}$. Arquimedes acreditava que nada do que existe é tão grande que não possa ser medido; por isso, aperfeiçoou o sistema grego de numeração, usando uma notação cômoda para os números muito grandes, semelhante ao atual sistema exponencial. Finalmente, deixou para o mundo um princípio que leva seu nome, o princípio de Arquimedes, que deduz o peso de um corpo imerso em um líqüido.

Sua dedicação à Geometria era tal que freqüentemente era levado ao banho contra sua vontade pelos seus servos, para lavá-lo e limpá-lo, e mesmo lá ele continuava desenhando figuras geométricas. $\mathrm{E}$ enquanto eles o estavam limpando e ungindo com óleos perfumados, ele desenhava linhas com o dedo sobre o óleo, completamente absorto, quase em estado de êxtase e transe, prova do prazer que tinha em estudar Geometria.

É bem possível que o que se conhece dele seja um misto de fato e ficção. É o cientista que conta com o maior número de mitos, talvez justamente por ter vivido num passado tão remoto e por ter se destacado de uma maneira tão fantástica e indelével. Grandes homens escreveram sobre ele (Diodoro Sículo, Eratóstenes, Plutarco, Cícero, Vitrúvio...) mas poucos relatos sobreviveram ao tempo. Sua vida, portanto, pertence à História e à Lenda.

Até a descoberta de seu famoso princípio, o princípio de Arquimedes, está envolta num apólogo: Hierão, rei de Siracusa, desejava oferecer aos deuses uma coroa de ouro e, para isso, contratou um ourives, a quem forneceu uma porção em prata e outra de ouro em pó. Quando a coroa foi entregue ao rei, este desconfiou que não havia sido empregado na sua confecção todo o ouro em pó que ele entregara ao ourives. Na impossibilidade de provar o roubo, Hierão consultou Arquimedes. Sempre preocupado com o problema que lhe fora apresentado, Arquimedes observou um dia, quando tomava banho, que à medida que seu corpo mergulhava na banheira, a água subia pelos bordos. Imediatamente percebeu como poderia solucionar o problema, e conta-se que ele teria saído pelas ruas, completamente nu, gritando "Heureca! Heureca!", isto é, "Achei! Achei!" . Depois preparou dois blocos, um de ouro e outro de prata, ambos com o mesmo peso da coroa. Mergulhou cada um deles, separadamente, em dois recipientes cheios de água, e mediu a quantidade de água que transbordou de cada recipiente. Se os volumes fossem iguais, a coroa era de ouro puro. Se tivesse uma mistura de prata (que é menos densa que o ouro), a coroa teria um volume maior (a saber, a densidade da prata é de $10,5 \mathrm{~g} / \mathrm{cm}^{3}$ enquanto que a do ouro é de 19,5 $\mathrm{g} / \mathrm{cm}^{3}$. Verificou, por esse processo, que os volumes de água deslocados pelos dois blocos eram diferentes, concluindo por estabelecer, com certa precisão, as massas de ouro e de prata empregadas na confecção da coroa de Hierão. Determinou portanto, os pesos específicos do ouro e da prata, e provou que o ourives estava roubando o rei. Por seu crime, o ourives foi morto. Alguns autores, porém, dizem que Arquimedes interferiu na decisão do rei. Adonias Filho[1] em "A vida de Arquimedes: o maior dos sábios da Antigüidade", escreve que Arquimedes "como recompensa, queria que o perdão fosse concedido. E isso porque, afinal, não fosse o joalheiro, a Física não teria tão cedo uma das suas leis mais importantes".

Agradecemos ao anônimo árbitro desta revista pela referência que fêz a uma outra versão existente deste episódio, publicada em 1891 na obra "Sur l'histoire de la balance hydrostatique et de quelques autres appreils et procédés", de M. Berthelot. Nas suas exatas palavras:

"Berthelot descreve, em primeiro lugar, o problema que Arquimedes estava tentando solucionar por ocasião da suposta exclamação $\epsilon \varepsilon \rho \eta \chi \alpha$ e informa que foi $\mathrm{Vi}$ truvius, no De architectura, livro 9, cap. 3, o autor

\footnotetext{
${ }^{2}$ Em livros de divulgação científica, é comum verem-se atribuídas a Arquimedes tais invenções. Muitos historiadores da ciência, porém, contestam essas afirmações.
} 
mais antigo conhecido que descreveu a suposta solução de colocar a coroa em um recipiente cheio de água $e$ medir a água derramada. Mas logo depois Berthelot comenta que esse procedimento não teria grande precisão, pois seria necessário utilizar um recipiente com boca muito larga (para poder colocar a coroa), e a medida da água derramada teria baixíssima precisão lé preciso levar em conta a tensão superficial...]. Depois, Berthelot assinala que Galileu já havia criticado a versão de Vitruvius, sugerindo que Arquimedes provavelmente havia utilizado uma balança hidrostática, ao invés do método da água derramada. Berthelot analisa então uma série de textos medievais, mostrando que de fato o método da balança hidrostática era descrito em tratados técnicos para resolver problemas semelhantes ao da coroa. Berthelot discute em seguida se esse método poderia ter vindo de Arquimedes, ou se seria uma invenção árabe transmitida à Europa durante o período medieval, e localiza um poema latino do século IV ou $V$ d.C. onde está descrito o uso da balança hidrostática para resolver o problema da coroa, e onde esse método é explicitamente atribuído a Arquimedes. Comprova, assim, a existência de uma tradição bastante antiga que interpreta de outra forma a solução de Arquimedes".

Recentemente (agosto/2000) o problema da coroa também foi analisado no artigo "Arquimedes e a coroa do rei: problemas históricos", de Roberto de Andrade Martins[2], publicado no periódico "Caderno Catarinense de Ensino de Física", volume 17, n? 2, de agosto de 2000:

"Há elementos um pouco estranhos na história. Porque motivo alguém encheria uma banheira até a borda? Para molhar todo o chão onde a pessoa ia tomar banho? Se o banho havia sido preparado por um escravo (uma hipótese plausivel), ele próprio teria que secar todo o chão, depois. Não é muito razoável pensar que ele enchesse a banheira até a borda.

Vitrúvio não viveu na época de Arquimedes e sim dois séculos depois, portanto suas palavras não constituem uma informação de primeira mão. Em que tipo de fonte ele baseou-se? Não o sabemos. (...)

Basta um pouco de bom senso para perceber que esse método de medida de volume não pode funcionar. Suponhamos que a coroa do rei tivesse um diâmetro da ordem de $20 \mathrm{~cm}$. Então, seria preciso utilizar um recipiente com raio superior a $10 \mathrm{~cm}$, cheio de água, e medir a mudança de nível ou a quantidade de líquido derramado quando a coroa fosse colocada lá dentro. Suponhamos que a massa da coroa fosse da ordem de $1 \mathrm{~kg}$ e que a sua densidade (por causa da falsificação) fosse de $15 \mathrm{~g} / \mathrm{cm}^{3}$ (um valor intermediário entre a densidade do ouro e a da prata). Seu volume seria então de 67 $\mathrm{cm}^{3}$. Colocando essa coroa no recipiente cheio de água, cuja abertura teria uma área superior a $300 \mathrm{~cm}^{2}$, o nível do líquido subiria uns 2 milímetros. É pouco plausível que fosse possivel medir essa variação de nível ou medir a quantidade de líquido derramado com uma precisão suficiente para chegar a qualquer conclusão, por causa da tensão superficial da água. Se o recipiente estivesse totalmente cheio, ao mergulhar a coroa dentro dele, poderia cair uma quantidade de líquido muito maior ou muito menor do que o volume da coroa (ou mesmo não cair nada). Portanto, é fisicamente pouco plausível que Arquimedes pudesse utilizar esse tipo de método."

Conta-se que, noutra vez, um navio, construído para o rei Hierão, era pesado demais para ser lançado ao mar, mas Arquimedes, com uma combinação de alavancas e polias, realizou a tarefa, maravilhando o rei.

A maioria dos mitos que cercam Arquimedes, entretanto, reside na sua brilhante luta em impedir que Siracusa fosse tomada pelos romanos. Além de físico e matemático notável, Arquimedes foi também um engenheiro criativo, que por três anos, com as suas invenções balísticas, adiou a tomada de Siracusa pelos romanos.

Arquimedes já era um ancião de 74 anos quando foi convocado a colocar em prática todo seu conhecimento nos ramos da matemática e da física para defender Siracusa. Naquele ano de 213 a.C., desenvolvia-se a Segunda Guerra Púnica e os romanos se esforçavam por dominar todo o Mediterrâneo, somando forças na guerra contra os cartagineses. Siracusa era um base importante na Sicília e o comandante Marcelo foi incumbido de tomar rapidamente a cidade. Sua frota logo se postou à frente dos muros da cidade e descarregou uma chuva de pedras e flechas sobre os soldados da linha de defesa. Em seguida, ergueu-se um largo conjunto de escadas, destinado a permitir o desembarque rápido e massivo de soldados. Naquele momento, no entanto, o exército local, dotado de engenhos desenvolvidos por Arquimedes, reagiu violentamente ao ataque.

Diz-se que Arquimedes teria construído catapultas que dilaceraram os navios romanos, lançando-lhes pedras de cerca de 50 quilogramas (dispararam também peças de betume em chamas que incendiaram vários barcos adversários); noutro ataque, teria montado no litoral uma máquina semelhante a um moderno guindaste, provida de uma enorme garra de ferro locomotora que "abraçava" os navios romanos. Quando os navios ficaram a uma distância suficiente, a garra foi acionada: subiu aos céus, desceu sobre os navios, aprisionou-os e os elevou de forma abrupta a até 10 metros acima da linha da água. Para terror dos soldados romanos, a garra deixou cair suas presas, fazendo os navios despencarem no mar, todos tortos e estraçalhados, afundando em poucos minutos.

O comandante Marcelo bateu em retirada e, em discurso direcionado aos soldados, comparou os engenhos de Arquimedes a um gigante de cem braços. O novo plano colocado em prática pelos romanos consistia em sitiar a cidade e vencer os gregos pela fome. Outras investidas infrutíferas se sucederam, até que os espiões romanos anunciaram uma rara oportunidade de ataque. Os defensores baixaram a guarda depois de uma festa em honra da deusa Artemisa. Embriagados e cansados, 
foram finalmente derrotados.

Arquimedes foi morto por um soldado romano, apesar das ordens de Marcelo para que o geômetra fosse poupado. Porque não ignoravam quem era Arquimedes, os romanos o enterraram com honras e, em seu túmulo, puseram as suas figuras favoritas, a esfera e o cilindro. Diz-se que Marcelo reservou para si, como parte do saque, engenhosos planetários que Arquimedes tinha construído para representar os movimentos dos corpos celestes.

A mais fantástica de todas as lendas, (e que aqui será discutida) diz respeito aos famosos espelhos ustórios. O sábio grego salvou a sua cidade incendiando a frota romana com raios solares concentrados por espelhos postos na costa. Teria ele utilizado um único e enorme espelho para isso ou vários espelhos menores? Se usou vários espelhos, quantos de um metro quadrado, por exemplo, seriam necessários para incendiar uma porção de madeira escura a cem metros de distância em menos de um minuto? Os espelhos deveriam ser curvos ou planos?

Primeiramente deve-se observar que os espelhos existentes na época eram de bronze polidos com areia, não sendo possível conseguir imagens muito nítidas. Apenas em 1291 os espelhos de vidro foram inventados. Apesar do vidro já ser conhecido pelos egípcios desde 2500 a.C., ninguém ainda tivera a idéia de usá-lo como espelho. Assim, Arquimedes só pôde ter utilizado escudos de bronze polidos.

Se os espelhos fossem planos, Arquimedes teria tido dificuldades em concentrar os raios solares de maneira a queimar rapidamente um objeto, a não ser que a quantidade de espelhos utilizada tenha sido considerável. Este problema ficaria resolvido se ele tivesse usado espelhos côncavos. Surge, porém, um novo problema: o foco dos espelhos côncavos é fixo, e os navios eram alvos móveis. Assim, os espelhos só seriam eficientes dentro de uma certa distância.

Homens ilustres discutiram a veracidade da história dos espelhos: Descartes não lhe dava crédito, Galileu sim. Ao longo da História, foram feitos vários testes para verificar se a proeza de Arquimedes seria possível na prática:

Na obra "Grande arte da luz e da sombra", de 1646, o padre jesuíta alemão Athanasius Kircher ${ }^{3}$ [1602 - 1680] relatou as experiências que fez com espelhos planos e discutiu essa suposta façanha de Arquimedes. Ele constatou que, com cinco espelhos planos dispos- tos apropriadamente, obtém-se um calor "quase intolerável" a mais de cem pés (33 metros) de distância. Com mais espelhos, os efeitos tornam-se impressionantes. Kircher, além disso, foi à própria cidade de Siracusa e deduziu que Arquimedes não tinha necessidade de um espelho de longo alcance. Ele sabia que um espelho parabólico só seria eficaz se o navio visado estivesse situado exatamente no foco e ficasse imóvel. Essas condições eram difíceis de preencher. Por isso, ele concluiu que Arquimedes teria atingido mais facilmente seu objetivo com uma bateria de espelhos planos ${ }^{4}$.

Em 1747, Georges Louis Leclerc, conde de Buffon ${ }^{5}$. [1707 - 1788] realizou várias experiências em Paris para tentar concluir alguma coisa sobre os espelhos ardentes de Arquimedes. Numa delas, utilizando apenas 98 espelhos incendiou "uma prancha forrada com betume e enxofre, colocada a 150 pés de distância" (cerca de 50 m). E ainda "o Sol estando muito fraco e encoberto, foi possível chamuscar com 154 espelhos uma prancha forrada com betume a 150 pés de distância." Noutra experiência utilizou um espelho composto por 168 vidros planos medindo 6 polegadas por 8 (cerca de $15 \mathrm{~cm}$ por $20 \mathrm{~cm}$ ). Ele conta que "no dia 10 de abril, depois de meio-dia, com um sol claro, conseguimos incendiar uma tábua de pinho forrada de betume, a 150 pés (cerca de $50 \mathrm{~m}$ ) com apenas 128 espelhos. Ela se inflamou instantaneamente em toda a extensão do foco, que media aproximadamente 16 polegadas (cerca de $40 \mathrm{~cm}$ ) naquela distância." Já com 148 espelhos, "o fogo foi tão violento que foi preciso mergulhar a prancha na água para apagá-lo". Em mais uma experiência, o foco estando a 20 pés de distância, "conseguimos derreter com 45 espelhos um grande vaso de estanho que pesava cerca de seis libras; e com 117 espelhos derretemos lâminas finas de prata e tornamos rubra uma placa de zinco". Após todas essas experiências, sobre o feito de Arquimedes, Buffon concluiu: "Devo conceder a Arquimedes e aos antigos a glória que lhes é devida; é certo que Arquimedes pôde fazer com espelhos de metal o que fiz com espelhos de vidro."

As experiências de Buffon tiveram vasta repercussão na época, como registra o Grande dicionário universal, de Pierre Larousse, da segunda metade do século 19: graças a Buffon, a reação foi completada, desmentindo a tese de Descartes, que declarara serem impossíveis os espelhos de Arquimedes".

\footnotetext{
${ }^{3}$ Kircher ganhou reputação européia pela sua erudição e também por possuir uma viva imaginação (escreveu um livro de ficção sobre viagens interplanetárias). Estudou os hieróglifos egípcios e traduziu vários nomes árabes de estrelas. Freqüentemente é atribuída a Kircher a invenção da lanterna mágica, sem a qual o cinema não teria nascido. Descrita pela primeira vez em "Grande arte da luz e da sombra", a lanterna mágica é uma inversão da câmara escura. Enquanto na câmara escura as imagens se projetam de fora para dentro, na lanterna mágica elas o fazem de dentro para fora.

${ }^{4}$ À falta da obra original, valemo-nos do depoimento de Pierre Thuillier[3].

${ }^{5}$ Buffon foi um célebre naturalista francês e um dos mais ilustres escritores. Seus dois grandes méritos foram o desenvolvimento sem igual por ele dado ao Jardim do Rei (atual Jardim botânico e Zoológico) do qual foi diretor a partir de 1739, e a redação, ou pelo menos a direção geral, da obra "História natural geral e particular" (44 volumes de 1749 a 1804, vários dos quais póstumos). Muitos outros assuntos interessavam a Buffon, que foi industrial [1767 - 1780], tradutor de Hales e de Newton, inventor da lente graduada para faróis, precursor da teoria da evolução e das pesquisas paleontológicas, bem como eficiente homem de negócios.
} 
Em 1973 o engenheiro grego Ioannis Sakkas utilizou como espelhos superfícies de dimensões comparáveis às dos escudos dos soldados gregos (cada um com cerca de $1,7 \quad 0,70 \mathrm{~m})$. Para não se distanciar muito da realidade histórica, cuidou até de modificar a superfície de seus painéis de vidro, recobrindo-os com uma fina película de bronze não muito polida. Depois de preparar desta forma sessenta e seis "escudos-espelhos", confiou-os a seus ajudantes, que, no Pireu, concentraram os raios solares sobre um modelo reduzido de galera (comprimento: $3,60 \mathrm{~m}$ ), que flutuava a cerca de $50 \mathrm{~m}$ de distância. Quando os homens puseram os espelhos na posição indicada, em dois minutos o barco incendiouse e em poucos segundos foi consumido pelas chamas. Pode-se dizer então que Arquimedes tinha condições de realizar a proeza, tanto porque algumas das galeras romanas em Siracusa estavam ligadas entre si, para servir de suporte às sambucas (um tipo de torre destinada ao assalto das fortificações). Tais conjuntos, pouco móveis e vulneráveis, teriam certamente constituído um bom alvo para os espelhos incendiários.

Ainda assim, os cientistas britânicos Allan Mills e Robert Clift, da Universidade Leicester resolveram realizar mais testes práticos para verificar se tal artifício de defesa seria realmente possível. Conseguiram reunir 440 peças de espelho (cada uma com um metro quadrado) em uma encosta. O calor produzido foi capaz de incendiar uma tábua a 50 metros de distância. Eles atentaram para o fato que, mesmo se Arquimedes tivesse conseguido a proeza, a chama poderia ser facilmente apagada com um balde d'água jogado por um soldado romano. No trabalho "Reflections on the burning mirrors of Archimedes, with a consideration of the geometry and intensity of sunlight reflected from plane mirrors", publicado por eles no "European Journal of Physics", em 1992, os cientistas afirmam que para incendiar apenas um barco romano utilizando um único espelho Arquimedes necessitaria de um espelho de 420 metros quadrados, impossível de se construir na época!

Tais pesquisadores esqueceram, no entanto, de atentar para dois fatos: primeiro, os registros históricos existentes não afirmam que Arquimedes mirou na madeira dos barcos romanos. Estes utilizavam velas, e pano é muito mais fácil de se queimar do que madeira; segundo, o elemento surpresa. Saberiam os romanos se defender de um fenômeno que eles não conheciam? Como podiam explicar o fato de seus barcos queimarem aparentemente sem motivo algum? Certamente ficaram desnorteados, e esse era mais um trunfo de Arquimedes. Sobre esta questão, diz Pierre Thuillier[3] no seu livro "De Arquimedes a Einstein":

"Incendiar ou semear o pânico?".

Pode-se também inventar numerosas variantes. $E$ imaginar, entre outras coisas, que os espelhos ardentes não serviram essencialmente para incendiar os navios mas para atemorizar e confundir os marinheiros...

Mais tarde, alguns historiadores teriam embelezado um pouco as coisas. Um episódio secundário foi então ampliado a ponto de constituir um experimento maravilhoso, digno do 'divino Arquimedes'. Esta interpretação, aliás, não é nova. É encontrada, por exemplo, no historiador D. E. Smith ${ }^{6}$ : 'Não há nada de improvável na idéia de que Arquimedes tenha podido usar seus espelhos ardentes pelo menos na idéia de tornar a situação insustentável para os soldados romanos'. Louis Figuier ${ }^{7}$, no século XIX, tinha dito isso em termos semelhantes: 'Somos da opinião de que é com razão que se atribui a Arquimedes o emprego de espelhos planos ou côncavos para perturbar, senão para incendiar, a frota de Marcelus'. Caso isso tenha acontecido, o silêncio do historiador Políbio está explicado: os espelhos ardentes desempenharam apenas um papel acessório, e ele não teria se detido em comentá-los."

Já Adonias Filho[1] dá a seguinte versão em "A vida de Arquimedes: o maior dos sábios da Antigüidade":

"Muralha pesada e grossa protegia Siracusa por terra. Arquimedes, e para que os inimigos não percebessem, ordenou o maior reforço na parte interior, por dentro, com centenas de homens nesse trabalho dia $e$ noite. Essa muralha tinha a espessura média de cinco metros que aumentava o dobro nos contrafortes. Construíra-se, em sua parte superior, um parapeito grosso com seteiras que também se viam a pouca distância do solo e na altura de um homem. Existiam várias fendas encobertas por folhas de carvalho que, já bastante sólidas, foram reforçadas com trancas de ferro. Uma folha larga, também de ferro, cobria o portão pelo lado de fora.

Escavou-se um fosso largo e profundo e para ele desviaram as águas de um riacho. E, no fundo desse fosso, por sugestão de Arquimedes, encravaram estacas pontiagudas que impediriam que os inimigos os franqueassem a nado. Estenderam-se cordas entre uma e outra estaca de madeira que, quem quer que se lançasse à água, não sairia com facilidade de semelhante labirinto. E, além disso, cavaram-se diversos fojos ${ }^{8}$ em sua proximidade onde puseram estacas pontiagudas que muito bem se dissimulavam na cobertura de caules que ligeira camada de terra ocultava.

Aproximar-se da muralha, pois, era uma tarefa arriscada e dificilima quanto mais que outras precauções foram tomadas. Ergueram-se, por exemplo, várias fogueiras, com abundante provisão de lenha, e ao lado puseram enormes caldeirões para que, no momento oportuno, neles se esquentasse o azeite. Arquimedes fez instalar aparelhos estranhos - projetores de bronze polido que concentravam e projetavam raios de sol em um

\footnotetext{
${ }^{6}$ SMITH, D. E., History of mathematics, Dover, 1958 (1 $1^{\text {a }}$ edição 1923), v. 1, p. 111 - 112.

${ }^{7}$ FIGUIER, Louis. "Vie des Savants illustres. Savants de l'Antiquité", Libraire internationale (Paris) 1866, p.242

${ }^{8}$ Fojo: Cova disfarçada e cheia de estrepes e pontas para apanhar o inimigo.
} 
único foco - que, em sua projeção de luz e calor, abria queimaduras nos soldados. E, para aumentar os seus efeitos, dotou-os de movimento ao redor de um eixo e com alça na parte posterior, através da qual se tornava fácil girá-los. Concentravam-se facilmente os raios solares, apesar da mobilidade dos atacantes, sobre qualquer um deles. E, considerando as defesas já erguidas nas imediações da muralha, Arquimedes calculou o foco dos espelhos de projeção para que alcançassem uma distância de sessenta e oito côvados ${ }^{9}$.

- Há apenas um inconveniente - ele disse, explicando - e é que só podemos colocá-los na muralha que dá para o Sul. As partes Oeste e Norte, porque não recebem os raios solares, não serão beneficiadas.

Os famosos e lendários espelhos de Arquimedes. É certo, porém, que não os empregou contra a armada romana porque, para ter algum resultado, necessitaria de tempo razoável com as naus, imóveis, na espera. Mas, ao contrário, armas terríveis eram os espelhos contra os soldados da infantaria e cavalaria que avançassem contra a muralha. E, quando não matavam homens $e$ animais, queimava-os ou cegava-os, gerando o pânico e o medo."

Assim, fica a pergunta: Arquimedes incendiou a frota romana? Há evidências contra e a favor da realização desse feito. Diz a lenda que o sábio teria tido conhecimento da capacidade dos espelhos em concentrar os raios solares quando, sentado em seu jardim, começou a sentir calor em uma das pernas. Olhando para ela, viu um círculo de luz queimante projetado nela. Tal círculo provinha de um escudo de bronze que estava apoiado numa coluna de pórtico, todo reluzente de sol. Assim, até a descoberta dessa propriedade dos espelhos está envolta num apólogo.

Se algum dia for confirmado que Arquimedes e em seguida Proclo, o primeiro em Siracusa e o segundo em Constantinopla, construíram poderosos espelhos cáusticos, não há porquê se surpreender, especialmente no caso do sábio de Siracusa. É incontestável que o engenheiro, físico, geômetra e matemático Arquimedes era imaginativo e habilidoso. Fabricou modelos mecânicos reproduzindo a marcha dos planetas e escreveu um tratado (hoje perdido) sobre o assunto. Ninguém contesta, ao que parece, que tenha também construído catapultas, guindastes e outros engenhos com a finalidade de erguer cargas enormes. Por que seus dons inventivos não lhe teriam servido para elaborar uma arma incendiária?

Para finalizar, do que foi exposto conclui-se que:

a) Arquimedes tinha condições, ainda que rudimentares, de realizar a façanha.

b) Se realizou a façanha, Arquimedes não utilizou um único e grande espelho.

c) Provavelmente utilizou espelhos planos no lugar de côncavos, ou talvez (por que não?) uma bateria mista de espelhos (planos e côncavos.) d) Se mirou os raios solares nos navios, mirou-os nas velas deles, e não na madeira (pois esta seria a atitude mais lógica a ser feita). É provável que os raios luminosos também tenham ofuscado os soldados romanos e que o próprio fogo das velas tenha chamuscado a madeira dos navios.

\section{Galileu, mitos e con- trovérsias}

Há três histórias famosas que cercam Galileu. A primeira diz que ele teria descoberto a lei do isocronismo das oscilações pendulares ao observar um lustre balançando; a segunda, que ele, para provar a lei da queda simultânea dos corpos, teria soltado ao mesmo tempo vários objetos do alto da Torre de Pisa (até mesmo uma bala de canhão e uma pena, e verificado que haviam chegado juntas ao solo!); a terceira, que ele teria murmurado "Eppur, si muove", depois de ter sido obrigado a negar o sistema heliocêntrico diante do Tribunal da Inquisição.

A primeira lenda, a do lustre, é bem possível que seja verdadeira. Sabe-se que Galileu, como cristão, costumava ir a Igrejas rezar. Aos 19 anos, ele teria recebido na Universidade de Pisa a visita do pai, Vicenzo, que tendo sido noticiado de seu péssimo desempenho na medicina (matéria que a princípio Galileu deveria estudar com prioridade), fora pedir explicações. Galileu revelou-lhe, então, que não estava interessado na medicina e que preferia muito mais matemática e física. Vicenzo voltou para Florença, onde morava, naquela mesmo dia, decepcionado pelo filho ter trocado a medicina, que ele julgava uma ciência nobre, pela matemática, para ele uma ciência de sonhadores, deixando Galileu triste e sem dinheiro.

Pouco após a ida do pai, Galileu resolveu entrar na catedral de Pisa para rezar. Nela, alguns operários estavam trabalhando num canto afastado do templo, erguendo um monumento ao túmulo de um cardeal falecido recentemente. Galileu notou que um lustre suspenso, no qual algum dos operários segurando uma viga devia ter esbarrado enquanto passava, oscilava lentamente, e que as oscilações, embora fossem diminuindo pouco a pouco de amplitude, duravam sempre o mesmo tempo, fato que pôde comprovar contando suas próprias pulsações. Fez, assim, a primeira de uma série de descobertas que se seguiriam: o isocronismo das oscilações pendulares, que logo proporia para ser utilizada na regularização dos relógios.

Há, porém, várias versões da cena do lustre. Eis como a descreve James Reston Júnior[4], na página 33 de seu livro "Galileu, uma vida":

"Ao que se diz, o estudante (Galileu) assistia ao serviço religioso num domingo na catedral, quando sua

\footnotetext{
${ }^{9}$ Côvado: Medida de comprimento equivalente a $0,66 \mathrm{~m}$.
} 
mente se desviou das vésperas monocórdias e seu olhar topou com uma lanterna decorativa, pendurada por um longo fio do teto lacunar no centro da nave. A chama da lanterna tremeluzia com a corrente de ar dentro da grande igreja, e a lanterna oscilava constantemente, de um lado para o outro, com a regularidade da... pulsação! Ecco! (...).

Essa foi a primeira lenda em torno de Galileu".

Quanto à segunda lenda, a maioria dos historiadores tende a considerá-la fantasiosa. Teria Galileu realmente lançado pesos da Torre de Pisa? Fez algumas experiências nesse sentido, decerto: deixou bolas de peso diferente rolarem numa inclinação suave. Eis a descrição de uma experiência feita por ele, no livro "Discursos e demonstrações matemáticas sobre duas novas ciências", de 1638:

"Em uma régua, ou mais exatamente uma viga de madeira, medindo cerca de seis metros de comprimento e com a espessura de três dedos, cavamos um pequeno canal com pouco mais de um dedo, perfeitamente retilíneo; em seguida o guarnecemos com uma folha de pergaminho bem lustrosa, para torná- lo o mais escorregadio possivel, e deixamos correr sobre ele uma bola de bronze bem duro, perfeitamente redonda e polida. Colocando então o aparelho numa posição inclinada e elevando uma das extremidades a $50 \mathrm{~cm}$ ou um metro acima do horizonte, nós deixamos, como já disse, a bola rolar sobre o canal (...) anotando o tempo necessário para uma descida completa. A experiência foi repetida várias vezes, a fim de determinarmos exatamente a duração do tempo, mas sem que nunca descobríssemos uma diferença superior à décima fração de um batimento de pulso. Depois de colocar a bola no lugar e tomar essa primeira medida, fazíamos com que ela descesse somente a quarta parte do canal; o tempo medido era sempre e rigorosamente igual à metade do tempo precedente. Em seguida, variamos a experiência, comparando o tempo necessário para percorrer a metade e os dois terços, ou três quartos, ou uma outra fração; repetindo essa experiência mais de cem vezes, verificamos sempre que os espaços percorridos estavam entre si como os quadrados dos tempos, fosse qual fosse a inclinação do plano, ou seja, do canal pelo qual se fazia descer a bola."

A situação é semelhante àquela dos corpos pesados caindo verticalmente, mas é de mais fácil observação, porque as velocidades desenvolvidas são menores. A mensuração de Galileu indicava que todos os corpos aumentavam sua velocidade à mesma razão, independente do peso de cada um. Não há quase nada que indique que ele atirou objetos da famosa Torre de Pisa. Apesar disso, escreve James Reston Júnior[4], na página 50 de sua biografia "Galileu, uma vida":
"Ele (Galileu) subiu na Torre de Pisa. A ousadia dessa idéia estava em seu caráter óbvio - porém ninguém antes dele havia pensado nela ou ousara tentála. O problema residia em medir o grau de queda livre. Haveria melhor lugar para conduzir a experiência do que esse monumento próximo às imperfeições humanas? Se Aristóteles argumentava que uma bola de cem libras caindo de uma altura de cem cúbitos atinge o solo antes que outra bola de uma libra tenha descido uma distância de um cúbito, quão fácil seria confirmar ou abalar essa assertiva. (Cem cúbitos eqüivalem a 58,4 metros; a Torre de Pisa mede 54 metros.)

Subindo a escada de caracol, ele carregou bolas de diferentes pesos e medidas - de chumbo e ébano, talvez até de ouro e pórfiro e cobre. Mais tarde, ele imaginaria a diferença entre as trajetórias de um ovo de galinha $e$ de um ovo de mármore. Diz a lenda que ele apregoou sua demonstração amplamente, atraindo uma multidão entusiasmada de estudantes e professores. Emergindo expansivamente no topo, entre pilastras e precárias arcadas abertas, ele representou para sua multidão. Ele foi aclamado clamorosamente. Estranhas vaias despontaram entre as aclamações, pois a maioria da turba sem dúvida esperava testemunhar um fiasco. Havia algo na torre que parecia atrair os excêntricos e os exibicionistas. Quem era aquele jovem gênio, aquele radical, para desafiar não apenas as autoridades no campo, mas o próprio Aristóteles? Talvez se assemelhasse ao corcunda que supostamente construíra a torre inclinadamente para alardear sua própria deformidade!"

O fato é que o próprio Galileu não escreveu sobre essa experiência. A lenda originou-se de alguns trechos que o primeiro biógrafo de Galileu, Vicente Viviani ${ }^{10}$ [1622- 1703], escreveu.

Alguns historiadores pensam que Viviani teria forjado a história. Outros, que Galileu, contando suas aventuras a Viviani, teria inventado heroísmos de juventude. $\mathrm{Na}$ verdade, foram os biógrafos românticos que insistiram na história da Torre de Pisa. A bem da verdade, embora Galileu não tenha descrito sua suposta experiência de forma clara à época, fê-lo indiretamente mais tarde. Em "Discursos e demonstrações matemáticas sobre as duas novas ciências" ${ }^{11}$, de 1638, há a seguinte passagem:

"Digo que as bolas atingem o solo ao mesmo tempo. Ao fazer a experiência, você descobre que, quando a massa mais pesada toca o solo, a mais leve está dois dedos mais distante. Agora você está enfatizando meu minúsculo erro, enquanto se esquece do grande erro de 99 cúbitos de Aristóteles"

Mais adiante nessa obra, ele diria que bolas de ouro, chumbo, cobre e pórfiro de mesmo peso revelariam apenas diferenças ínfimas no tempo de chegada quando jo-

\footnotetext{
${ }^{10}$ Viviani tinha 17 anos quando passou a estudar com Galileu, em 1639.

${ }^{11}$ Nesta obra Galileu volta a escrever na forma de um diálogo entre três personagens: Simplício (que encarna a filosofia tradicional, herdada em especial de Aristóteles); Sagredo (um homem de mente aberta) e Salviati (que encarna o próprio Galileu). A primeira vez que Galileu havia feito isso foi no livro "Diálogo concernente aos dois principais sistemas do mundo", de 1632.
} 
gadas de torres. Assim, parece que Galileu teria realizado uma experiência envolvendo pesos jogados de torres. O historiador francês de origem russa Alexandre Koyré [1822 - 1964], contudo, em sua obra "Estudos Galileanos" [1940], afirma que tais descrições não passam de um exercício mental de Galileu, uma experiência imaginária: se a resistência do ar fosse removida, ou se as bolas caíssem no vácuo - postulou Galileu - cairiam exatamente na mesma velocidade!

Essa é a opinião de Koyré. É necessário repetir: opinião. Até hoje nenhum historiador provou a fantasia dessa lenda. O assunto ainda é suscetível de discussões. Pode-se dizer com certeza, porém, que é falsa a história em que Galileu teria lançado uma pena e uma bala de canhão do alto da Torre de Pisa para provar a queda simultânea dos corpos. Tal experiência só poderia dar certo no vácuo!

Para completar a análise desse mito, é posto aqui um texto de Richard Brennan[5], encontrado a partir da página 20 de seu livro "Gigantes da Física", que bem mostra a importância das experiências do sábio italiano (Brennan descrê da lenda da torre):

"Segundo uma história interessante, que infelizmente não passa de um mito, Galileu deixou cair objetos de diferentes pesos da inclinada Torre de Pisa para demonstrar que cairiam sobre a terra na mesma velocidade. Essa história não é mencionada por Galileu em nenhuma de suas anotações; na verdade, foi atribuída a ele anos mais tarde. Seja como for, o experimento, tivesse ele sido efetuado, não teria tido os resultados presumidos, porque objetos de diferentes pesos só cairiam na mesma marcha no vácuo.

$O$ que Galileu de fato fez foi estudar como os objetos se movem, não deixando que caíssem livremente da torre ou de qualquer outro lugar, mas usando um plano inclinado. Fazendo bolas de diferentes pesos rolarem por um plano inclinado abaixo, tornou o movimento mais lento até o ponto em que podia medi-lo. Não era um experimento perfeito porque havia atrito envolvido e objetos mais pesados seriam mais afetados que outros mais leves. Galileu fez o possivel para eliminar esse fator, polindo a tábua inclinada até deixá-la lustrosa. Começou com uma inclinação suave e em seguida repetiu o experimento com inclinações crescentes, até que a velocidade se tornou grande demais para ser medida com alguma precisão. Galileu foi capaz de extrapolar os resultados desses experimentos com declives, concebendo um experimento hipotético mental para conjeturar o que ocorreria a objetos numa queda livre. Descobriu que um objeto em queda não cai simplesmente ele cai cada vez mais depressa ao longo do tempo. Em outras palavras, ele se acelera, e a aceleração (aumento de velocidade) é constante. Além disso, Galileu observou que a taxa de aumento da velocidade é a mesma para todas as esferas, seja qual for seu peso ou tamanho. Sendo um matemático, expressou todas as suas conclusões numa fórmula que é conhecida como a Lei da queda dos corpos. Não precisamos detalhar a matemática ou a fórmula, mas cabe simplesmente assinalar que hoje se considera que as observações e deduções de Galileu deram início à ciência da mecânica e que tiveram enorme influência sobre Isaac Newton".

Outro mito afirma que Galileu, após abjurar ajoelhado as suas idéias perante a Inquisição, teria se levantado e dito: "Eppur, si muove", isto é, "No entanto (a Terra) se move". Isso é invenção de um biógrafo romântico. A primeira menção a essa citação está num livro editado na França em 1789. É falsa, portanto, essa história. Constitui um fato, porém, que intimamente Galileu nunca renegou suas idéias.

Também é ficção que Galileu tenha passado pela tortura. Sempre foi tratado como um grande senhor. Os instrumentos de tortura nem chegaram a lhe ser mostrados, como era de praxe na época. Em 1755, o francês Pierre Estève, no seu livro História da Astronomia, escreveu que a Inquisição furou-lhe os olhos. Está certo que Galileu ficou cego, mas não por esse motivo, e sim porque adquiriu catarata.

Por fim, inúmeros livros de divulgação científica dizem que, apesar de Galileu não ter sido o inventor da luneta, tem o mérito de ter sido o primeiro a apontá-la para o céu. Isso, porém, é uma informação equivocada. O primeiro homem a apontar uma luneta para os céus foi um inglês chamado Thomas Harriot [1560 - 1621], o primeiro cartógrafo da Lua, contemporâneo de Galileu, que não publicou suas observações [11].

\section{A maçã de Newton}

Talvez a mais famosa de todas as lendas que envolvem os grandes cientistas seja esta: a maçã de Newton. Como toda história consagrada pelo tempo, existem algumas variantes que cercam essa lenda (alguns dizem que a maçã caiu na cabeça do cientista, outros, aos pés dele, por exemplo) mas a versão mais comumente contada é a seguinte: conta-se que Newton estava sentado certo dia sob uma macieira e um fruto dessa árvore caiu em sua cabeça. O episódio teria dado a Newton imediata compreensão da força universal da gravidade.

Essa, sem dúvida, é a mais fantasiosa de todas as versões, e, ao invés de enaltecê-lo, faz de Newton um completo estúpido, pois era necessário uma maçã cair na cabeça dele para ele descobrir que existe uma força dominante no Universo? Ele por acaso não via as coisas caírem? Não poderia ter deduzido isso de outras maneiras não tão esdrúxulas?

Este artigo não visa questionar o intelecto de Newton e sim analisar até onde pode haver verdade nesse episódio, bem como mostrar as controvérsias do mesmo.

Esse episódio tornou-se famoso por dois motivos: primeiro, porque aconteceu com um gênio (Newton), que morreu rico e consagrado mundialmente; segundo, porque foi contado por um homem famoso, o filósofo 
francês Voltaire [1694 - 1778], que afirmou ter ouvido a história de uma sobrinha de Newton. Voltaire narra o fato no seu livro "Filosofias de Newton", de 1738:

"Um dia no ano de 1666, Newton, então em sua fazenda, vendo uma fruta cair de uma árvore, segundo me disse sua sobrinha, Mme. Conduit, começou a meditar profundamente sobre a causa que atrai todos os corpos na direção do centro da Terra".

Alguns eminentes astrônomos como Carl Sagan[6] [1934 - 1996], negavam qualquer veracidade nessa história. Na sua obra "Os planetas", escrita conjuntamente com Jonathan Norton Leonard, lê-se na página 15:

A Lua, um corpo que cai

"Newton não descobriu a gravitação observando a queda de uma maçã nem sendo por ela atingido conforme reza a lenda popular. As leis relativas à queda dos corpos haviam sido amplamente estudadas, mas se aplicavam somente à superfície da Terra. Não havia idéia da gravitação como força universal, afetando todos os objetos, onde quer que se encontrassem. Evidentemente, raciocinava-se na época que tais leis não se aplicavam aos corpos celestes, pois eles não caem para a Terra. Newton mostrou seu gênio utilizando as leis das quedas dos corpos para a Lua, que não caía.

Viu por experiência que um objeto atirado horizontalmente segue trajetória tanto menos curva quanto mais velocidade tenha. Newton raciocinou que talvez a velocidade da Lua, cerca de 3700 quilômetros por hora, fosse suficiente para fazê-la seguir sua conhecida trajetória, a despeito da tendência para cair, como outros objetos. Em uma inspirada estimativa baseada nas propriedades matemáticas das elipses de Kepler, admitiu que, quando aumenta a distância da Terra, a força de sua gravitação diminui segundo o quadrado da distância.

Não foi bem um sucesso a primeira tentativa de Newton em aplicar tal idéia à Lua, mas, quando conseguiu melhor estimativa do tamanho da Terra, deu admirável resultado. Na realidade, a Lua se movia com a exata velocidade para que a gravitação da Terra, atenuada pela distância, a mantivesse em órbita. Newton conseguira uma coisa extraordinária, um dos maiores feitos na história do pensamento humano. Usara a conhecida força que faz as coisas caírem sobre a Terra, para explicar porque a Lua não caía."

Afinal, o que nessa história pode ser estabelecido como fato?

É fato que a casa de Newton, em Woolsthorpe, possuía um jardim com várias macieiras. O cenário para a lenda, portanto, existe. O episódio teria ocorrido em 1666, quando Newton tinha, portanto, 23 anos. Seu livro, "Princípios Matemáticos da Filosofia Natural", em que expõe o conceito e as leis da gravitação universal, foi publicado em 1687. Transcorreram-se, portanto,
21 anos desde o episódio até que as leis da gravitação estivessem suficientemente desenvolvidas para serem divulgadas nos ambientes científicos.

Essa mesma observação consta na página 51 da obra "A vida de Isaac Newton" de Richard Westfall[7], o renomado biógrafo de Newton:

"Não surpreende que essa historieta, que faz lembrar a associação judaico-cristã da maçã com o conhecimento, continue a ser repetida. Juntamente com o mito do annus mirabilis e com a anotação de Newton que dizia haver ele constatado que o cálculo tinha uma correspondência muito próxima, ela tem contribuido para a idéia de que a gravitação universal surgiu diante de Newton num lampejo de discernimento, em 1666, e de que ele carregou os Principia para lá e para cá durante 20 anos, essencialmente concluídos, até Halley conseguir soltá-los e entregá-los ao mundo. Formulado dessa maneira, esse relato não resiste a uma comparação com o histórico dos primeiros trabalhos de Newton na mecânica. Ele banaliza a gravitação universal, tratando-a como uma idéia brilhante. Uma idéia brilhante não consegue moldar uma tradição científica."

O que deve, então, ter acontecido realmente? Se ele tivesse tido compreensão instantânea da gravitação universal quando a maçã caiu-lhe na cabeça, teria ele levado dois decênios para escrever sua obra-prima? Tendo em vista os fatos históricos, o leitor pode perfeitamente concluir que, da maneira como foi contada, a história da maçã é absurda e inverossímil. A versão mais plausível do que deve ter acontecido parece ser a contada por John Conduitt ${ }^{12}$ [1688 - 1737], marido da sobrinha de Newton. Essa é outra dentre as quatro versões independentes que existem:

"No ano de 1666, ele tornou a se afastar de Cambridge (...) indo ter com a mãe em Linconshire, $e$ quando meditava num jardim, ocorreu-lhe que o poder da gravidade (que derrubara uma maçã da árvore no chão) não estava limitado a uma certa distância da Terra, mas deveria estender-se muito além do que se costumava pensar. 'Por que não até a Lua?'- disse ele a si mesmo, e, se assim fosse, isso deveria influenciar seu movimento e talvez mantê-la em sua órbita."

Explanando-se a versão de Conduitt, pelo que ainda se sabe da vida de Newton, percebe-se melhor como a queda da maçã influenciou a descoberta da gravitação: num dia de 1666, Newton estava sentado contemplativamente debaixo de uma macieira, quando foi surpreendido pela queda de uma maçã. Há tempos Newton estudava a teoria de Kepler sobre as leis dos movimentos planetários, e foi levado por esse pequeno incidente a refletir sobre que tipo de força puxa os corpos para o centro da Terra. Perguntou-se, também, até onde iriam os limites dessa força. Por que não se estenderia esse poder até a Lua e, nesse caso, por que a Lua, bem maior do que uma maçã, não caía sobre a Terra? O que

\footnotetext{
${ }^{12}$ John Conduitt casou-se com a sobrinha de Newton, Catherine Barton [1679 - 1739], em 26 de agosto de 1717. Sentia profunda admiração por Newton. Escreveu resumos de suas conversas com ele e reuniu várias histórias sobre ele.
} 
mantinha esse astro orbitando a Terra? Essa mesma indagação se formou na sua mente com respeito aos planetas, que se movem em volta do Sol. De raciocínio em raciocínio, chegou assim Newton à concepção da grande teoria, que seus cálculos não tardaram em confirmar. O livro "Princípios Matemáticos da Filosofia Natural" aborda muitos outros temas além da gravitação; esse foi um dos motivos da demora em sua publicação. A maçã de Newton é citada como exemplo dos resultados de grande importância, que muitas vezes derivam de causas insignificantes.

Em plena concordância do que acabou de ser exposto, cita-se por fim um trecho da obra "Gigantes da Física", de Richard Brennan[5], referente à lendária maçã de Newton, situado na página 36 :

"A história de que a idéia da gravitação universal foi sugerida a Newton pela queda de uma maçã parece verdadeira. William Stukeley ${ }^{13}$, o primeiro biógrafo de Newton, relata que ouviu o caso dele próprio. Ao observar o fato, Newton deu um salto mental intuitivo e fez a si mesmo uma pergunta básica: e se a mesma força responsável pela queda da maçã se estendesse à orbita da Lua? Em primeiro lugar, presumiu que a Lua estava caindo em direção à Terra em resposta ao puxão para baixo (vertical) da gravidade da Terra, mas jamais se chocava com esta por causa do puxão horizontal, mais forte, do Sol. Supôs que a Lua, à medida que cai em direção à Terra, é também puxada horizontalmente, no grau exatamente necessário para compensar a queda e carregá-la em torno da curvatura da Terra em sua órbita elíptica. Em segundo lugar, imaginou que a força gravitacional emanaria do centro de um corpo (a Terra, neste caso) e não de sua superfície. Tentou então quantificar a diferença entre a força exercida sobre a maçâ e aquela exercida sobre a distante Lua. Realizou esta última tarefa tomando por base a terceira lei do movimento planetário de Kepler, chegando ao que se tornou conhecido como a lei do inverso do quadrado. $A$ força gravitacional diminui com o inverso do quadrado da distância sobre a qual se propaga. Se a maçã estivesse 60 vezes mais próxima do centro de gravidade da Terra do que a Lua (como de fato está), a força gravitacional exercida sobre a maçã seria 60 ao quadrado, ou 3.600 vezes mais forte que aquela experimentada pela Lua. Inversamente, portanto, a Lua deveria se curvar para baixo ao longo de sua órbita (queda) 1/3600 avos do que a maçã cai no mesmo tempo. A partir dessas suposições, Newton pôde calcular a órbita exata da Lua.

A elaboração matemática de tudo isso confirmou a magnífica intuição de Newton de que a mesma força que puxa a maçã para baixo, puxa a Lua. Em seguida, ele deu mais um passo gigantesco para a humanidade ao pressupor que aqueles mesmos princípios matemáticos se aplicavam a todos os corpos - planeta, lua ou asteróide - no universo. De fato, Newton tomara o quadro geral do Universo de Descartes e o tornara rigorosamente matemático e preciso. Havia feito nada menos que construir a primeira síntese moderna sobre o universo físico, uma visão fundada na mecânica, em que tanto as menores partículas quanto os maiores corpos celestes movem-se todos de acordo com os mesmos princípios matemáticos."

É sabido que a ciência freqüentemente passa pelos caminhos do ocasional, mas logo é redirecionada para a análise, a pesquisa, o trabalho intelectual. Um caminho difícil, como se percebe, mas de méritos muito maiores.

Muitas maçãs haviam caído antes de Newton nascer. E nunca alguém antes dele havia se perguntado porquê, ao invés de caírem no chão, as maçãs não subiam até o céu, perdendo-se no Universo, ou porque elas não deveriam algumas vezes cair, outras vezes subir, outras vezes moverem-se para algum lado. Tais perguntas eram consideradas pelas pessoas comuns desinteressantes e até idiotas. O homem comum, que se acha cheio de bom senso e aceita o mundo como tal é, sem se fazer perguntas absurdas, nunca descobriu nada e nunca criou nada. Newton, ao contrário, fez a "pergunta idiota" e descobriu, gradualmente, a lei da gravitação universal. Outro episódio da vida de Newton que tornou-se motivo para contestações é relativo aos seus chamados "anos admiráveis" ${ }^{14}$. Em 1665, um surto de peste obrigou as universidades a fecharem as portas. Richard Westfall[7] assim relatou o caso na página 38 de sua obra:

"No verão de 1665, uma calamidade abateu-se sobre muitas partes da Inglaterra, inclusive Cambridge. 'Aprouve a Deus Todo-poderoso, em sua justa severidade', como disse Emmanuel College, 'castigar esta cidade de Cambridge com a praga da pestilência'. Embora Cambridge não tivesse como saber disso e pouco tenha feito, nos anos seguintes, para aplacar a severidade divina, a provação de dois anos foi a última vez em que Deus optou por castigá-la dessa maneira. Em $1^{\text {O }}$ de setembro, o governo municipal cancelou a Feira de Sturbridge e proibiu todas as reuniões públicas. Na verdade, os colégios tinham feito as malas e se dispersado muito antes disso. O Trinity registrara, em 7 de agosto, a decisão de que 'todos os professores e alunos que forem agora para o interior em virtude da pestilência deverão receber as verbas usuais para seu sustento pelo prazo do mês subseqüente'. Os registros do ecônomo deixam claro que o colégio, embora antecipando-se à universidade, ficou atrás de muitos de seus residentes, que já haviam fugido e, por conseguinte, não receberam a verba relativa ao último mês do trimestre de verão. Durante oito meses, a universidade ficou quase deserta. Em meados de março, não tendo havido nenhum regis-

${ }^{13} \mathrm{O}$ médico Stukeley conheceu Newton no início de 1718, com o qual fez amizade. Ao se mudar para Grantham posteriormente, Stukeley fez questão, à semelhança de Conduitt, de colher informações sobre Newton.

${ }^{14}$ Anos admiráveis: Denominação dada ao período de dois anos (de 1664 a 1666) de recolhimento forçado passado por Newton em Woolsthorpe, período que este aproveitou para desenvolver as suas mais importantes idéias. 
tro de morte em seis semanas, a universidade convidou seu corpo docente e discente a voltar. Em junho, ficou claro que o castigo divino ainda não se havia encerrado. Houve um segundo êxodo e a universidade só pôde retomar seu pleno funcionamento na primavera de 1667 ".

Isaac Newton deixou a Universidade de Cambridge para uma permanência forçada na sua casa de Woolsthorpe, onde pôde estudar à vontade. Na página 39 do livro de Richard Westfall[7], consta o relato de Newton sobre esse período:

"No início do ano de 1665, descobri o método de aproximação a uma série desse tipo e a regra para reduzir qualquer potência de qualquer binômio para tal série. No mesmo ano, em maio, descobri o método das tangentes de Gregory e Slusius e, em novembro, obtive o método direto das fluxões, e no ano seguinte, em janeiro, a teoria das cores, e em maio seguinte desvendei o método inverso das fluxões e, no mesmo ano, comecei a pensar na gravidade como se estendendo até a órbita da Lua e (depois de descobrir como calcular a força com que [um] globo girando dentro de uma esfera pressiona a superfície da esfera), a partir da regra de Kepler de que os períodos dos planetas estão numa proporção sesquiáltera com suas distâncias do centro de suas órbitas, deduzi que as forças que mantêm os planetas em suas órbitas devem [variar] reciprocamente, como o quadrado de sua distância do centro em torno do qual eles giram: e a partir disso, comparei a força necessária para manter a Lua em sua órbita com a força da gravidade na superfície da Terra, e descobri que elas se correspondem bem de perto. Tudo isso foi nos dois anos da peste, 1665-1666. Pois, nessa época, eu estava no auge de minha fase de invenção e me interessava mais pela matemática e pela filosofia do que em qualquer ocasião posterior."

Nem todos os historiadores crêem que Newton tenha feito tudo isso em sua curta estada de 17 meses no campo. Isso porque esse relato foi escrito a propósito da controvérsia do cálculo, cuja prioridade Newton disputou ferrenhamente com Leibniz. Assim essa crença ficou situada na categoria de mito, ao lado da história da queda da maçã. Esse é o caso, por exemplo, do próprio Richard Westfall. Escreve ele na página 59 de seu livro "A vida de Isaac Newton":

"Ante um exame minucioso, os anni mirabiles revelam-se menos miraculosos do que o annus mirabilis do mito newtoniano. Quando 1666 chegou ao fim, Newton não estava de posse dos resultados que tornaram sua reputação imortal, nem na matemática, nem na mecânica, nem na óptica. O que ele fizera nessas três áreas fora lançar bases, algumas mais extensas do que outras, sobre as quais pudesse construir com segurança, porém nada estava concluído no fim de 1666 , $e$ a maior parte nem sequer chegava perto de estar concluída. Longe de diminuir a estatura de Newton, este juízo a aumenta, por tratar suas realizações como um drama humano de esforço e luta, e não como uma história de revelação divina."

De fato, de documentos, pouca coisa há que comprove (ou descarte) as palavras de Newton. Porém, como bem argumentou Richard Brennan[5] na página 39 de sua já citada obra, "na ausência de prova em contrário, é opinião deste autor que se deveria aceitar a palavra de Newton como expressão do que aconteceu e do momento em que aconteceu".

\section{A idéia luminosa de Edison}

Tomás Alva Edison nasceu em 11 de fevereiro de 1847 e morreu em 18 de outubro de 1931. É considerado até hoje o mais profícuo inventor do mundo! Autodidata, sua primeira invenção data de 1868, e consistia num contador automático de votos, que não obteve sucesso. Durante seus 84 anos de vida, ele e sua equipe patentearam mais de 1000 inventos, dentre eles: o telégrafo duplo, que permitia serem transmitidas simultaneamente duas mensagens num mesmo fio e em sentidos contrários; o fonógrafo, em 1877 (o modelo original deste último era um cilindro recoberto por cera que girava em torno de seu eixo, enquanto um estilete registrava sulcos que permitiam reproduzir os sons. Alguns anos mais tarde Edison requereu registro para o modelo que utilizava discos); aparelhos telegráficos quádruplos e sêxtuplos e o cinescópio (1891). Em 1883 Edison havia descoberto a emissão de elétrons por metais incandescentes, que é a origem da lâmpada de diodo.

A mais popular de suas invenções, contudo, é a lâmpada elétrica incandescente. Isso, porém, é um mito:ao contrário do que popularmente se diz, Edison não inventou a lâmpada elétrica. Vários modelos de lâmpada elétrica incandescente já haviam sido apresentados ao mundo antes de Edison. Ignácio de Loyola Brandão[8], na página 93 de seu livro "Tomás Edison", explica:

"Edison não inventou a luz (elétrica). Apesar de ser reconhecido popularmente por ela, através dos tempos, o que na verdade ele fez foi dar o toque de gênio: aperfeiçoá-la. O problema da lâmpada elétrica era bastante complexo. Sua realização tinha sido tentada por umas dez pessoas. Ao menos, sabe-se que dez chegaram a um resultado mais satisfatório, conseguindo elaborar uma lâmpada que se acendia por alguns momentos. Em 1820, na França, De La Rive apresentou uma lâmpada incandescente. Houve depois as experiências de De Moylens, em 1841, J. W. Starr, em 1845, Joseph Swan, um inglês, que produziu lâmpadas incandescentes usando carvão ou platina como condutores, a partir de 1848. Os russos Kohn e Lodyguine chegaram muito perto. Outro russo, Jablochkoff iluminou a avenida da ópera com 64 lâmpadas, durante a Exposição Internacional de Paris. Nos Estados Unidos, Moses Farmar já tinha iluminado a sala de sua casa com pequenas 
lâmpadas construídas com fios de platina e irídio. E Sawyer tinha conseguido uma patente protegendo uma lâmpada cujos fios eram de platina.."

Os problemas das lâmpadas incandescentes da época eram basicamente dois: davam luzes de diferentes intensidades, sempre muito fortes, e não suportavam ficar acesas mais que alguns minutos. Ao serem aquecidas, os condutores de corrente elétrica logo se fundiam.

Na busca de um material durável que servisse como filamento ${ }^{15}$ para a lâmpada, Edison usou praticamente de tudo: algodão, bário, borracha vulcanizada, carvão, crina de cavalo, platina, ródio, rutênio, seda, titânio, zircônio... usou até fio de barba de um de seus ajudantes! Como se vê, Edison andava praticamente às cegas. O material que deu melhores resultados foi mesmo o algodão carbonizado. Atualmente, o filamento das lâmpadas elétricas é de tungstênio, por ser o metal de mais elevado ponto de fusão $\left(3410{ }^{\circ} \mathrm{C}\right)$.

Assim, o que Edison fez foi popularizar a energia elétrica, tornando-a barata. O máximo que se pode dizer é que Edison inventou um modelo econômico de lâmpada elétrica incandescente. Sem seu trabalho e esforço, certamente a eletricidade permaneceria por muito tempo como um artigo de luxo e cara. Esse é o mérito de Edison (o que não é pouco). Não se pode, porém, esquecer o trabalho dos outros cientistas.

\section{O zero de Einstein}

A crença popular diz que o grande físico alemão Albert Einstein [1879 - 1955], naturalizado americano, já tirou zero em matemática. A origem deste mito provavelmente é esta: as notas escolares alemães vão de 6 a 1 (1 é a nota máxima): $1=\operatorname{sehr}$ gut (muito bom); $2=$ gut (bom); $3=$ befriedigend (satisfatório) $; 4=$ ausreichend (suficiente); $5=$ mangelhaft (fraco), $6=$ ungenügend (insuficiente). Assim, é possível que os primeiros biógrafos de Einstein tenham interpretado erroneamente seu boletim. Na verdade, Einstein era excelente em aritmética. Para seu infortúnio, entretanto, a mesma excelência não se verificava nas outras disciplinas escolares.

Outra crença, que dessa vez nada tem de popular e costuma ser espalhado por pessoas pedantes (e ignorantes) é que Einstein teria dito a seguinte frase: "Tudo é relativo". Einstein nunca disse isso. Pelo contrário, segundo Einstein existe pelo menos uma coisa absoluta nesse mundo: a velocidade da luz (no vácuo), pois é constante e independe da velocidade relativa da sua origem e do observador: 300.000 .000 de metros por segundo!

O mais recente mito que há em torno de Einstein diz respeito a uma filha que ele teria tido em 1902, chamada Lieserl. A história só emergiu em 1986, dando lugar a várias historietas que procuram desvendar o que teria

\footnotetext{
${ }^{15}$ A palavra "filamento" foi inventada por Edison.
}

acontecido à filha do eminente cientista. Toda e qualquer novidade é noticiada pelos meios de comunicação, especialmente pelos jornais. No domingo de 5 de março de 2000, o jornal "O Globo" publicou na página 10 da seção "O País" uma pequena reportagem relatando as últimas descobertas dos biógrafos einsteinianos sobre a desaparecida Lieserl:

\section{NOVIDADES NO MISTÉRIO DA FILHA DE EINSTEIN}

"É possivel que se tenha achado o caminho que desvendará um dos maiores mistérios do século passado, o destino da filha de Albert Einstein.

Em 1902, aos 22 anos, Einstein teve uma filha com Mileva Maric, sua namorada e colega no Instituto Politécnico de Zurique. Eles viriam a se casar, mas da menina, chamada Lieserl, nada se soube. Só em 1986 é que se descobriu sua existência. Einstein só a mencionou numa carta, em 1903, e nunca mais falou do assunto. Em 1935, ao saber que havia uma mulher dizendo-se sua filha, contratou um detetive, sem qualquer sucesso. Soube-se apenas que a criança ficou na Sérvia, com a familia da mãe.

Einstein não foi o único responsável pelo sumiço da criança, visto que ele e Mileva viveram juntos por mais 17 anos e tiveram outros dois filhos (um dos quais esquizofrênico). Ele a abandonou, para casar-se com uma prima.

A escritora Michele Zackheim correu atrás do mistério durante cinco anos. Revirou lembranças e livros de paróquias. Perseguiu pistas que levavam a quatro mulheres que poderiam ter sido Lieserl (mas não eram). Não chegou a uma conclusão definitiva, mas convenceu-se de que a menina nasceu com deficiências mentais e morreu aos dois anos, de escarlatina.

A pesquisa de Zackheim está no seu livro, 'Einstein daughter: A dark chapter in the early life of Albert Einstein' ('A filha de Einstein: um capitulo negro na juventude de Albert Einstein, inédito em português). Pelo noticiário que o livro provocou, percebe-se que, mesmo sendo cautelosamente inconclusiva, a descoberta esbarra na história do detetive. Se Lieserl tivesse morrido durante o matrimônio do físico com Mileva, Einstein não tinha porquê procurá-la.

Zackheim trabalhou com a ajuda de uma jovem sérvia que estudava física nos Estados Unidos. Chamase Marija Dokmanovic. Ela ajudou-a traduzindo documentos sérvios e depois foi à luta por conta própria. Chegou a uma conclusão diferente. Lieserl teria chegado à idade adulta. Por enquanto, Dokmanovic recusa-se a revelar o nome dessa mulher, pois admite que lhe faltam provas.

Essa hipótese confere com as suspeitas do professor Robert Schulmann, da Boston University e guardião do 
papelório de Einstein. Ele contou (ao) escritor Denis Brian, magnífico biógrafo do cientista ('Einstein - uma vida', editado no Brasil) que Lieserl sobreviveu ao pai, que morreu em 1955. É possivel que Lieserl tenha vivido sem saber que era filha de Einstein. (...)"

O testamenteiro e grande amigo de Einstein, Otto Nathan, durante quase 35 anos impediu o acesso de pesquisadores aos arquivos, documentos e anotações pessoais do cientista. Neste trabalho de ocultação foi auxiliado pela leal secretária de Einstein, Helen Dukas, que com ele trabalhou durante 27 anos, e colecionou até mesmo os rascunhos e notas que ele atirava na cesta de lixo. Devotos, ambos lutaram para preservar a imagem quase canônica de Einstein que foi projetada - e, de certa forma também montada - pela mídia ao longo dos anos: cabeça grande, cabelos desgrenhados, roupas amarfanhadas e um inabalável bom humor.

Pouco antes de Otto Nathan morrer, em 1987, uma ação judicial tirou os arquivos de Einstein de suas mãos e abriu-os aos pesquisadores. São milhares de documentos. Uma pequena parcela do material, principalmente a correspondência de Einstein com a segunda mulher, Elsa, e com os filhos, ainda continua interditada. A parte tornada visível oferece material tão farto que, certamente, com o tempo, tornará públicas novas e surpreendentes revelações.

Denis Brian mergulhou nesses arquivos e, com pertinácia de repórter linha de frente, foi atrás de pessoas que conviveram com Einstein: cientistas, amigos, discípulos. A abertura dos arquivos e a circunstância de a maioria dos envolvidos mais diretamente já estarem mortos romperam as barreiras do silêncio obsequiso, e desta pesquisa resultou uma biografia reveladora e inteira sobre o Einstein "terreno".

No prefácio de "Einstein - A ciência da vida", Brian cita a evidência irrefutável da existência de uma filha ilegítima que o cientista jamais reconheceu:

"Descobri que a vida de Einstein é repleta de triunfos e de trágicas ironias. O cientista cuja mente o levou aos pontos mais distantes do espaço tinha um filho esquizofrênico que não conseguia atravessar a rua sozinho. $O$ pacifista, que literalmente não mataria uma mosca, foi obrigado a exigir a fabricação de uma bomba devastadora. O humanista que demonstrava carinho e interesse pelos filhos dos outros negligenciava os próprios e mantinha em segredo a existência de sua primeira filha, ilegítima. O amante da solidão vivia invariavelmente rodeado de mulheres, caçado pela imprensa $e$ assediado pelas multidões. E o democrata dedicado era constantemente acusado de comunista ou inocente útil a eles."

\section{Considerações finais}

Certamente seria proveitoso aos estudantes de nível fundamental e médio que os livros didáticos não apenas relatassem esses e outros mitos contados de geração em geração, mas também os discutissem, treinando o estudante para saber discernir o fantasioso do real, o improvável do plausível. São exemplos de livros com falta de discussão (e por conseguinte, carência ora de cientificidade, ora de historiografia, ora de ambos) as seguintes obras: "Termologia e Óptica", de Luís Alberto Guimarães[9] e Marcelo Fonte Boa, da Editora Harbra, de 1998, que na página 184 dá como certa, sem a menor discussão, a queima da frota romana supostamente realizada pelos espelhos cáusticos de Arquimedes:

“(...) Arquimedes aplicou, na prática, a reflexão da luz com fins não muitos pacíficos: utilizando grandes espelhos parabólicos, ele concentrou os raios solares sobre as velas de navios romanos que atacavam Siracusa, incendiando-os"

No ensino médio é lecionado Óptica, e o caso de Arquimedes poderia ser explorado em pequenos problemas que abordassem, por exemplo, as propriedades dos espelhos esféricos de Gauss (lembrando-se que Arquimedes não utilizou espelhos, e sim escudos de bronze polidos). Por exemplo, um professor poderia oferecer o seguinte problema aos seus alunos:

"Para Arquimedes queimar as velas de um navio romano que estivesse situado a 50 metros dele, valendo-se para isso de um único espelho côncavo que obedecesse às leis de Gauss, qual deveria ser o raio de curvatura desse espelho?"

No espelho côncavo, o foco é real (intersecção efetiva dos raios luminosos). Para queimar as velas da embarcação, esta deverá estar situada no foco do espelho. Sabe-se que o foco de um espelho esférico de Gauss situa-se aproximadamente na metade da distância entre o centro de curvatura do espelho e o seu vértice. Logo, Arquimedes teria que usar um espelho de raio de curvatura de 100 metros.

A obra "Os Fundamentos da Física", Volume 1, Mecânica, de Ramalho[10], Nicolau e Toledo, da Editora Moderna, 1999, na página 86 relata três mitos galileanos:

"Foi Galileu quem estabeleceu a lei da queda dos corpos, afirmando que, quando um corpo está caindo livremente, sua aceleração é constante e é a mesma para todos os corpos, leves ou pesados, grandes ou pequenos. Conta-se inclusive que Galileu teria realizado uma demonstração pública desse fato, abandonando simultaneamente vários corpos do alto da Torre de Pisa e verificando que chegavam juntos ao solo.

No campo da Astronomia, Galileu foi o primeiro homem a observar o céu com um telescópio".

Tal informação está equivocada, pois foi o inglês Thomas Harriot o pioneiro dessa façanha.

“(...) Por suas idéias revolucionárias e seu espírito rebelde, Galileu foi perseguido e condenado pela Inquisição. Para evitar um mal maior, Galileu concordou em abjurar publicamente suas teorias, negando inclusive que a Terra se movesse no espaço. Entretanto, 
consta que após sua abjuração, ao sair do tribunal, o genial cientista teria murmurado: E pur si muóve ("No entanto, se move')".

Na página 452 do mesmo livro, os autores contam um mito arquimediano:

"Quando uma pessoa está mergulhada nas águas de uma piscina ou do mar sente-se mais leve, como se o líquido estivesse empurrando seu corpo para cima, aliviando seu peso. Quem pela primeira vez verificou esse fato foi o cientista grego Arquimedes, durante um banho. Conta-se que, entusiasmado com a descoberta que lhe permitiu resolver um problema que o preocupava, Arquimedes saiu nu pelas ruas de sua cidade, gritando 'Heureca! Heureca!' "

Esses exemplos provam a presença marcante desses contos nos livros didáticos. Além de tirar dúvidas, a discussão dessas histórias mostraria como é o verdadeiro trabalho de um cientista, provando que sorte ajuda, e muito, mas não é suficiente para uma descoberta. Tal lição já foi enunciada há tempos pelo químico e biologista francês Louis Pasteur [1822 - 1895]. Foi ele quem disse: "No terreno da observação, a sorte favorece apenas os espíritos prevenidos".

\section{Referências}

[1] FILHO, Adonias. A vida de Arquimedes: o maior dos sábios da Antigüidade, Ediouro, Série "Os Grandes Personagens e a História", 1983.
[2] MARTINS, Roberto de Andrade. Arquimedes e a coroa do rei: problemas históricos, Caderno Catarinense de Ensino de Física, vol. 17, n⿳ 2, agosto de 2000.

[3] THUILLIER, Pierre. De Arquimedes a Einstein A face oculta da invenção científica, Coleção Ciência e Cultura, Jorge Zahar Editor, 1998.

[4] JÚNIOR, James Reston, Galileu, uma vida, Editora José Olympio, 1994.

[5] BRENNAN, Richard. Gigantes da Física - Uma história da física moderna através de oito biografias, Jorge Zahar Editor, 1998.

[6] SAGAN, Carl e LEONARD, Jonathan Norton. Os planetas, Livraria José olímpio Editora.

[7] WESTFALL, Richard S. A Vida de Isaac Newton, Editora Fronteira, 1995.

[8] BRANDÃO, Ignácio de Loyola. Thomas Edison, Coleção "Os Homens que mudaram a Humanidade", Editora Três, 1974.

[9] GUIMARÃES, Luís Alberto e BOA, Marcelo Fonte. Termologia e Óptica, Editora Harbra, 1998.

[10] RAMALHO, NICOLAU, TOLEDO. Os Fundamentos da Física, Vol. 1, Mecânica, Editora Moderna, 1999.

[11] MOURÃO, Ronaldo Rogério de Freitas. Dicionário Enciclopédico de Astronomia e Astronáutica. 1ª , Editora Nova Fronteira, 1987. 